Check for updates

Cite this: RSC Adv., 2018, 8, 14654

Received 19th December 2017

Accepted 3rd April 2018

DOI: 10.1039/c7ra13476b

rsc.li/rsc-advances

\section{Carbon-free energetic materials: computational study on nitro-substituted BN-cage molecules with high heat of detonation and stability $\dagger$}

\begin{abstract}
Xin Zeng, (D) Nan Li (D)* and Qingjie Jiao*
A new series of high-energy density materials (HEDMs) $\mathrm{B}_{6} \mathrm{~N}_{6} \mathrm{H}_{6-n}\left(\mathrm{NO}_{2}\right)_{n}(n=1-6)$ are studied at the M06$2 X / 6-311++G^{* *}, \omega B 97 X D / 6-311++G^{* *}$ and B3LYP/6-311++G** levels. Analysis of the structural changes caused by substituting the $\mathrm{NO}_{2}$ and the electronic structures, such as electron localization function (ELF), Wiberg bond index (WBI), charge transfer and bond dissociation energies (BDE), provide important insights into the essence of the chemical characteristics and stability. Moreover, the Born-Oppenheimer molecular dynamic (BOMD) simulation is performed to verify their stability, which suggests that only the $\mathrm{BN}$-cage derivatives with one and two nitro groups bonding with boron atoms $\left(\mathrm{NO}_{2}-1-1\right.$ and $\left.\mathrm{NO}_{2}-2-1\right)$ can remain stable under ambient conditions. To predict the detonation performance and sensitivity of these two stable BN-cage energetic molecules accurately, the density, gas phase enthalpy of formation, enthalpy of sublimation, detonation performance, impact sensitivity and BDE are calculated systematically. The calculation results show that both $\mathrm{NO}_{2}-1-1$ and $\mathrm{NO}_{2}-2-1$ have a higher heat of detonation, higher value of $h_{50}$, and larger BDE of trigger bonds than CL-20.
\end{abstract}

\section{Introduction}

High-energy density materials (HEDMs) with both superior detonation performance and low sensitivity have always drawn the attention of research scientists. ${ }^{\mathbf{1 1 1}}$ The increased energy density often comes at the expense of molecular stability. Seeking new HEDMS with a fine balance between high detonation performance and low sensitivity remains to be an interesting, but very challenging task.

It is recognized that the best known explosive with superior detonation performance is $2,4,6,8,10,12$-hexanitro-2,4,6,8,10,12hexaazatetracyclo[5.5.0.0.0]dodecane (HNIW or CL-20), which was successfully synthesized by Nielsen in $1987 .{ }^{12}$ Besides the energetic functional groups, the large strain energy of its cage skeleton also allows CL-20 to store a high amount of energy. Currently, boron containing energetic materials have captured a great deal of attention in energetic materials research. ${ }^{13-21}$ The addition of boron in both micro and nano sizes into energetic materials can increase the energy output effectively and improve the detonation properties due to its high heat of combustion (36.3 $\mathrm{kJ} \mathrm{mol}^{-1}, 1.9$ times than that of aluminum). ${ }^{13-21}$ Thus, from the point of view of energy release during combustion, boron-

State Key Laboratory of Explosion Science and Technology, School of Mechatronical Engineering, Beijing Institute of Technology, Beijing 100081, China. E-mail: leen04@bit.edu.cn; leen04@163.com; jqj@bit.edu.cn; jqjbit@126.com

$\dagger$ Electronic supplementary information (ESI) available. See DOI: 10.1039/c7ra13476b and nitrogen-containing complexes could be a good choice for developing high energy materials.

Inspired by this, we attempted to replace the $\mathrm{C}$ atoms of CL-20 with $\mathrm{B}$ atoms to develop a new carbon-free BN-cage energetic system. The nitro $\left(\mathrm{NO}_{2}\right)$ groups are bonded to the $\mathrm{BN}$-cage structure to increase the nitrogen and oxygen content, which can achieve a good oxygen balance. In this theoretical study, the $\mathrm{BN}$-cage and its $\mathrm{NO}_{2}$ derivates are systematically investigated to understand their stability, electronic structures, safety and detonation properties at the M06-2X/6-311++G**, $\omega \mathrm{B} 97 \mathrm{XD} / 6-311++\mathrm{G}^{* *}$ and B3LYP/6-311++G** levels of density functional theory (DFT). Through the systemic study of the above compounds, it is predicted that two $\mathrm{BN}$-cage derivatives, $\mathrm{NO}_{2}-1-1$ and $\mathrm{NO}_{2}-2-1$, will have a superior detonation performance and low sensitivity, and could therefore potentially be new HEDMs.

\section{Theoretical methods}

All quantum mechanical calculations in this paper were performed using the Gaussian-09 software package ${ }^{22}$ at the M06$2 \mathrm{X}, \omega \mathrm{B} 97 \mathrm{XD}$ and B3LYP level with the $6-311++\mathrm{G}^{* *}$ basis set. The M06-2X meta-hybrid density functional developed by Zhao and Truhlar is an advanced method to calculate energies, which have shown a good performance for main group chemistry and kinetics studies. ${ }^{23,24}$ For comparison, the theoretical methods of $\omega$ B97XD and B3LYP were also employed with the basis set of 6$311++\mathrm{G}^{* *}$. The $\omega \mathrm{B} 97 \mathrm{XD}$ method includes a $100 \%$ long-range exact exchange, a small fraction (about 22\%) of the short- 
range exact exchange, a modified B97 exchange density functional for a short-range interaction, and the B97 correlation density functional and empirical dispersion correction. ${ }^{25,26}$ $\omega$ B97XD yields satisfactory accuracy for thermochemistry and kinetics. The DFT method of B3LYP combines Becke's threeparameter (B3) ${ }^{27}$ functional with the Lee-Yang-Parr (LYP) ${ }^{28}$ correlation functional, which has been considered to be capable of accurately predicting the structural parameters and frequencies of many nitro-substituted compounds. ${ }^{29-31}$ Moreover, the $6-311++\mathrm{G}^{* *}$ basis set can generally give satisfactory geometries. ${ }^{32}$ All of the optimized molecular structures in this paper belong to local minima on their singlet spin state potential surface and have no imaginary frequency. Structures of the nitro-substituted BN-cage compounds are denoted as $\mathrm{NO}_{2}-n-\mathrm{N}$ in the present article, where $n$ is the number of energetic groups, $\mathrm{N}$ orders the structures according to their relative energies using the M06-2X method.

Calculation of the electron localization function (ELF), deformation energies, net charge and charge transfer at the same level are used to analyze the electronic structure and stability of the $\mathrm{NO}_{2}-n-\mathrm{N}$ series. Moreover, Born-Oppenheimer molecular dynamic simulations (BOMD) are employed to exam the stability of the designed cage compounds to select the stable $\mathrm{BN}$-cage derivates with a DFT in the level of M06-2X/6$311++\mathrm{G}^{* *}$. BOMD deals with the electronic and nuclear problems separately. In this method, the electronic structure in the ground state is calculated at each set of atomic positions, usually by optimization of the Kohn-Sham orbitals using an iterative method. ${ }^{33}$ The BOMD method in general needs more CPU time than for other MD software, but the method is more robust and stable.

Heat of detonation, detonation velocity and detonation pressure were calculated using EXPLO $5,{ }^{34}$ using the density and solid phase enthalpy of formation $\left(\Delta_{\mathrm{f}} H^{\circ}(\mathrm{s})\right)$. The gas phase enthalpy of formation $\left(\Delta_{\mathrm{f}} H^{\circ}(\mathrm{g})\right)$ and the enthalpy of sublimation $\left(\Delta H_{\text {sub }}^{\circ}\right)$ were used to calculate the solid phase enthalpy of formation $\left(\Delta_{\mathrm{f}} H^{\circ}(\mathrm{s})\right)$.

The following isodesmic reactions (1) combined with the computational Formula (2) were used to calculate the $\Delta_{\mathrm{f}} H^{\circ}(\mathrm{g})$ of the studied compounds.

$$
\begin{gathered}
\mathrm{B}_{6} \mathrm{~N}_{6} \mathrm{H}_{6}+n \mathrm{NO}_{2} \rightarrow \mathrm{B}_{6} \mathrm{~N}_{6} \mathrm{H}_{6-n}\left(\mathrm{NO}_{2}\right)_{n}+\frac{n}{2} \mathrm{H}_{2} \\
\Delta H_{298}=\Delta E+\Delta \mathrm{ZPE}+\Delta H_{\mathrm{T}}
\end{gathered}
$$

In eqn (1) and (2), $n$ is the number of nitro groups, $\Delta H_{298}$ is the enthalpy change of the reaction at $298 \mathrm{~K}, \Delta E$ is the change in total energy between the products and the reactants, $\Delta \mathrm{ZPE}$ is the change of zero-point energy between the products and the reactants, and $\Delta H_{\mathrm{T}}$ is the thermal correction from 0 to $298 \mathrm{~K}$.

Electrostatic potential analysis (ESP) is employed to analyze the molecular surface at the M06-2X/6-311++G level of theory. In the eqn (3)-(7), the electrostatic potential on the surface is characterized by $V_{\mathrm{s}}(r) . V_{\mathrm{s}}^{+}\left(r_{i}\right), V_{\mathrm{s}}^{-}\left(r_{i}\right)$ and $V_{\mathrm{s}}\left(r_{i}\right)$ represents the positive, negative and the overall value of $V_{\mathrm{s}}(\mathrm{r})$ at any point $r_{i}$ on the surface. The $\overline{V_{\mathrm{S}}{ }^{+}}, \overline{V_{\mathrm{S}}{ }^{-}}$and $\overline{V_{\mathrm{s}}}$ represent their averages, and ${\sigma_{+}}^{2},{\sigma_{-}}^{2}$, and ${\sigma_{\text {tot }}}^{2}$ are the corresponding variances. $\nu$ is the electrostatic balance parameter. $m$ and $n$ are the number of positions with positive and negative potentials on the molecular surface. The parameters mentioned above will be used to further calculate the enthalpy of sublimation, density and impact sensitivity in the corresponding equations.

$$
\begin{gathered}
\overline{V_{\mathrm{s}}^{+}}=\frac{1}{n} \sum_{i=1}^{n} V_{\mathrm{s}}^{+}\left(r_{i}\right) \\
\overline{V_{\mathrm{s}}^{-}}=\frac{1}{m} \sum_{i=1}^{m} V_{\mathrm{s}}^{-}\left(r_{i}\right) \\
\overline{V_{\mathrm{s}}}=\frac{1}{m+n}\left[\sum_{i=1}^{n} V_{\mathrm{s}}^{+}\left(r_{i}\right)+\sum_{i=1}^{m} V_{\mathrm{s}}{ }^{-}\left(r_{i}\right)\right] \\
\sigma_{\mathrm{tot}}{ }^{2}=\sigma_{+}{ }^{2}+\sigma_{-}{ }^{2} \\
=\frac{1}{n} \sum_{i=1}^{n}\left[V_{\mathrm{s}}^{+}\left(r_{i}\right)-\overline{V_{\mathrm{s}}^{+}}\right]^{2}+\frac{1}{m} \sum_{i=1}^{m}\left[V_{\mathrm{s}}{ }^{-}\left(r_{i}\right)-\overline{V_{\mathrm{s}}}\right]^{2} \\
V=\frac{{\sigma_{+}}^{2} \sigma_{-}{ }^{2}}{\left[\sigma_{\mathrm{tot}^{2}}{ }^{2}\right.}
\end{gathered}
$$

The enthalpy of sublimation $\left(\Delta H_{\text {sub }}^{\circ}\right)$ can be evaluated using the developed method by Rice and Politzer et al. ${ }^{35}$

$$
\Delta H_{\mathrm{sub}}^{\circ}=\alpha\left(A_{\mathrm{s}}\right)^{2}+\beta\left(v \sigma_{\mathrm{tot}^{2}}\right)^{0.5}+\gamma
$$

In eqn (8), $\alpha=0.000267, \beta=1.650087$, and $\gamma=2.966078$.

Then, the solid phase enthalpy of formation $\left(\Delta_{\mathrm{f}} H^{\circ}(\mathrm{s})\right)$ can be calculated using eqn (9).

$$
\Delta_{\mathrm{f}} H^{\circ}(\mathrm{s})=\Delta_{\mathrm{f}} H^{\circ}(\mathrm{g})-\Delta H_{\text {sub }}^{\circ}
$$

The crystal density $(\rho)$ of the studied compounds can be calculated using $\rho=\alpha_{1}\left(\frac{M}{V_{m}}\right)+\beta_{1}\left(\nu \sigma_{\mathrm{tot}^{2}}{ }^{2}\right)+\gamma_{1},{ }^{36}$ in which $\alpha_{1}=0.9183$, $\beta_{1}=0.0028$, and $\gamma_{1}=0.0443$.

In order to understand the sensitivity and safety of the studied cage compounds, the impact sensitivity, ${ }^{37}$ Wiberg bond index (WBI), ${ }^{38,39}$ and bond dissociation energy (BDE) ${ }^{40}$ were calculated. Impact sensitivity can be tested using the drop hammer test, which is measured by dropping a given mass (2.5 $\mathrm{kg}$ ) upon the compound and recording the height $\left(h_{50}\right)$ which has a $50 \%$ probability of producing an explosion. The value of $h_{50}$ is calculated using eqn (10). ${ }^{37}$

$$
h_{50}=\alpha_{2} \sigma_{+}^{2}+\beta_{2} \nu+\gamma_{2}
$$

In eqn (10), $\alpha_{2}=-0.0064, \beta_{2}=241.42$, and $\gamma_{2}=-3.43$.

The BDE is calculated using eqn (11). In general, if the value of BDE is greater than $84 \mathrm{~kJ} \mathrm{~mol}^{-1}$, the corresponding bond is considered to be stable.

$$
\mathrm{BDE}_{(\mathrm{A}-\mathrm{B})}=\left[E_{\mathrm{A}} \cdot+E_{\mathrm{B}} \cdot\right]-E_{(\mathrm{A}-\mathrm{B})}
$$




\section{Results and discussion}

\subsection{Configuration}

Fig. 1 shows an optimized structure of the designed BN-cage that was confirmed to be a global minimal without imaginary frequencies at the M06-2X level. The distances of B3-N7, B5-N6 and B16-N15 are 1.716 $\AA$, $1.716 \AA$ and $2.803 \AA$, respectively. The corresponding WBI, determined using natural bond orbital (NBO) analysis were $0.5085,0.5085$ and 0.0049 , respectively. The relatively long distance and small WBI between B16 and N15 suggests the absence of the corresponding bond. Additionally, the bond lengths (WBI) of B1-N8, B2-N9 and B4-N10 were found to be $1.370 \AA$ (1.2746), $1.403 \AA$ (1.0820) and $1.403 \AA$ (1.0820), respectively. The shorter bond lengths and larger WBI of these three bonds compared with the other $\mathrm{B}-\mathrm{N}$ bonds are indicative that double bonds exist between B1-N8, B2-N9 and B4-N10. Also, the topological analysis of the ELF was performed to understand the bond character of the $\mathrm{B}-\mathrm{N}$ bonds in the designed BN-cage. The corresponding color-filled maps and the curve maps of ELF for these bonds are shown in Fig. S1, $\dagger$ which further confirms the existence of the B3-N7, B5-N6, B1-N8, B2$\mathrm{N} 9$, and B4-N10 covalent bonds, and the inexistence of the B16N15 bond.

The $\mathrm{H}$ atoms in the designed $\mathrm{BN}$-cage were replaced by nitro groups to construct a series of new energetic molecules. All of the optimized structures could retain the integrity of the $\mathrm{BN}$ cages. Moreover, the calculation results indicated that the energetic groups bond with boron atoms in the cage led to lower-energy structures than that with nitrogen atoms. Fig. 2 shows the optimized geometries of the $\mathrm{NO}_{2}-n-1(n=1-6)$.

The four mononitro-substituted BN-cage compounds shown in Fig. S1 and Table $\mathrm{S} 2 \uparrow$ were found to lie less than $200 \mathrm{~kJ} \mathrm{~mol}^{-1}$ in energy above the lowest-energy structure $\mathrm{NO}_{2}-1-1$. The nitro group in the lowest-lying structures $\mathrm{NO}_{2}-1-1$ is bonded to the $\mathrm{B} 5$ atom by replacing $\mathrm{H} 12$ in the $\mathrm{BN}$-cage. It should be pointed out that the distance between $\mathrm{B} 3$ and N7 in $\mathrm{NO}_{2}-1-3$ is $2.621 \AA$, the

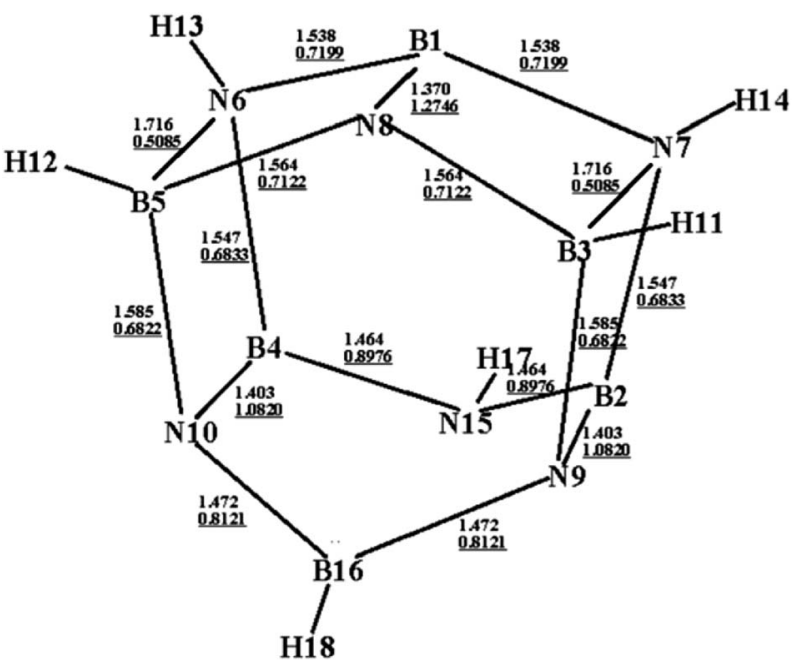

Fig. 1 Optimized structure (bond lengths in $\AA$ ) for the designed $B N$ cage at the M06-2X/6-311++G** level. Wiberg bond indexes are underlined. long distance of the bond and the corresponding ELF analysis (shown in Fig. S3†) suggests that the B3-N7 bond does not exist.

The five dinitro-substituted BN-cage compounds shown in Fig. S2 and Table $\mathrm{S} 3 \uparrow$ are found to lie less than $200 \mathrm{~kJ} \mathrm{~mol}^{-1}$ in energy above $\mathrm{NO}_{2}-2-1$. Similar to the mononitro-substituted compounds, the nitro groups bond with $\mathrm{B} 3$ and $\mathrm{B} 5$ in $\mathrm{NO}_{2}-2-1$ to obtain the lowest-energy structure with the symmetry of the $C_{\mathrm{S}}$. The $\mathrm{NO}_{2}-2-2$ lies at an energy of $27.2 \mathrm{~kJ} \mathrm{~mol}^{-1}$ above the $\mathrm{NO}_{2}$ 2-1S at the M06-2X level, having the $\mathrm{B} 5-\mathrm{NO}_{2}$ and $\mathrm{B} 16-\mathrm{NO}_{2}$ bonds. However, the $\mathrm{NO}_{2}-2-3, \mathrm{NO}_{2}-2-4$ and $\mathrm{NO}_{2}-2-5$, with the $\mathrm{N}-$ $\mathrm{NO}_{2}$ bonds have much higher total energies than the NO2-2-1 and NO2-2-2 due to the high energy of the $\mathrm{N}-\mathrm{N}$ bonds.

The four trinitro-substituted BN-cage compounds shown in Fig. S3 and Table $\mathrm{S} 4 \dagger$ are found to lie less than $200 \mathrm{~kJ} \mathrm{~mol}^{-1}$ in energy above the lowest-energy structure $\mathrm{NO}_{2}-3-1$. The three nitro groups in $\mathrm{NO}_{2}-3-1$ with a $C_{\mathrm{s}}$ symmetry are bonded with the B3, B5 and $\mathrm{B} 16$ atoms. The $\mathrm{NO}_{2}-3-2, \mathrm{NO}_{2}-3-3$ and $\mathrm{NO}_{2}-3-4$ with one $\mathrm{N}-\mathrm{NO}_{2}$ bond are, respectively, 126.0, 150.5 and $161.2 \mathrm{~kJ} \mathrm{~mol}^{-1}$ at the M06-2X level, higher than $\mathrm{NO}_{2}-3-1$.

As shown in Fig. S4 and Table S5, $\dagger$ three tetranitrosubstituted BN-cages are found to lie less than $200 \mathrm{~kJ} \mathrm{~mol}^{-1}$ in energy above $\mathrm{NO}_{2}-4-1$. Both of the first two structures $\mathrm{NO}_{2}-4-1$ and $\mathrm{NO}_{2}-4-2$ have three $\mathrm{B}-\mathrm{NO}_{2}$ bonds and one $\mathrm{N}-\mathrm{NO}_{2}$ bonds, while the $\mathrm{NO}_{2}$ groups in $\mathrm{NO}_{2}-4-3$ bond with two $\mathrm{B}$ atoms and two $\mathrm{N}$ atoms. It should be pointed out that the distances between the $\mathrm{B} 3$ and $\mathrm{N} 7$ atoms in $\mathrm{NO}_{2}-4-2$ and $\mathrm{NO}_{2}-4-3$ are 2.534 and $2.491 \AA$, respectively. The relatively long distances and the corresponding ELF analysis shown in Fig. S7 and S8† suggests the absence of corresponding bonds.

Only the two pentanitro-substituted BN-cages were found, which are shown in Fig. S5 and Table S6. $\dagger$ In $\mathrm{NO}_{2}-5-1$, the five nitro groups bond with the three boron atoms and two nitrogen atoms. Additionally, the distance of B3 $\cdots \mathrm{N} 7$ and B16 $\cdots \mathrm{N} 15$ in $\mathrm{NO}_{2}-5-1$ are 2.608 and $2.629 \AA$ respectively, which are about $1 \AA$ longer than the other $\mathrm{B}-\mathrm{N}$ bonds. This is indicative of the absence of these two bonds, combined with the color-filled map and the curve map of ELF (shown in Fig. S10 $\dagger$ ).

Finally, only one hexanitro-substituted $\mathrm{BN}$-cage $\mathrm{NO}_{2}-6-1$ is found, as shown in Fig. S6 and Table S7. $\uparrow$ All of the $\mathrm{H}$ atoms in the designed $\mathrm{BN}$-cage are replaced by nitro groups leading to the $C_{\mathrm{S}}$ symmetry for $\mathrm{NO}_{2}-6-1$.

\subsection{Electronic structure and thermal stability}

To study the change caused by substituting the $\mathrm{H}$ of the designed BN-cage with $\mathrm{NO}_{2}$, the deformation energies of the skeleton $\left(\Delta E_{\text {cage }}\right)$ and the relative $(\Delta \mathrm{BDE})$ are calculated and summarized in Table $1 . \Delta$ BDE can be calculated using eqn (12), which is the relative $\mathrm{BDE}$ of cage- $\mathrm{NO}_{2}$ bonds to the corresponding cage- $\mathrm{H}$ bonds in the designed BN-cage without substitution.

$$
\Delta \mathrm{BDE}=\mathrm{BDE}_{\text {cage- } \mathrm{NO}_{2}}-\mathrm{BDE}_{\text {cage-H }}
$$

$\Delta E_{\text {cage }}$ corresponds to the change of the BN-cage skeleton. The $\Delta E_{\text {cage }}$ shown in Table 1 indicates that the substitution of the nitro groups leads to the deformation of the cage skeleton. Adding nitro groups to the nitrogen atoms of the BN-cage brings 


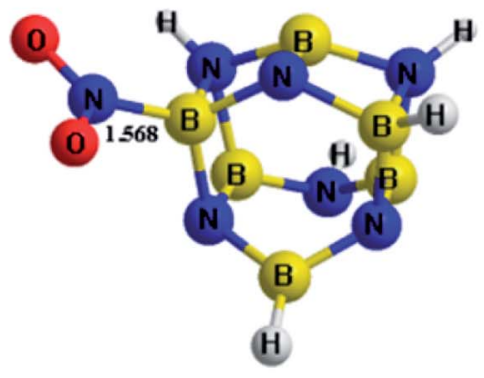

$\mathrm{NO}_{2}-1-1(\mathrm{Cl})$

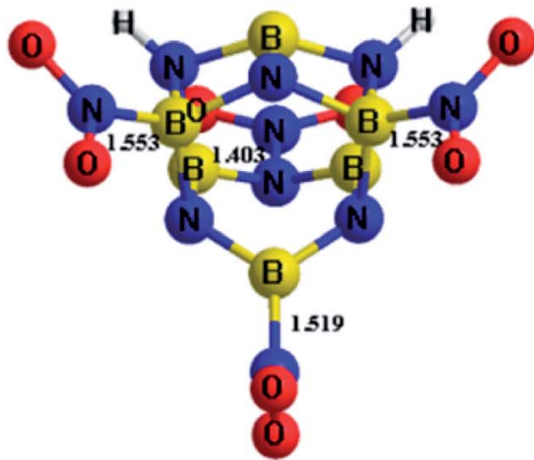

$\mathrm{NO}_{2}-4-1(\mathrm{Cs})$

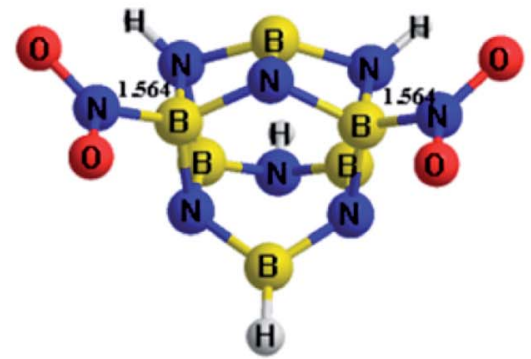

$\mathrm{NO}_{2}-2-1(\mathrm{Cs})$

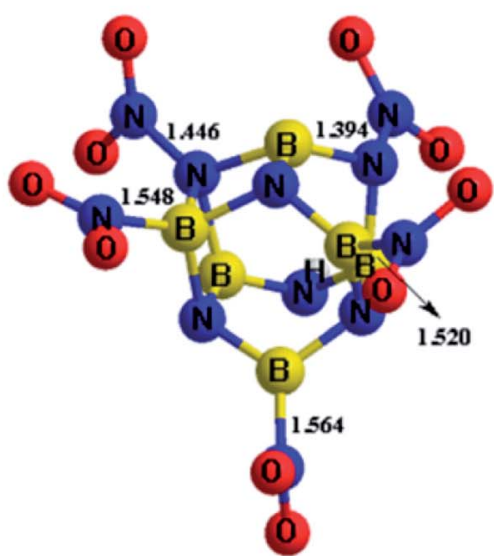

$\mathrm{NO}_{2}-5-1(\mathrm{Cl})$

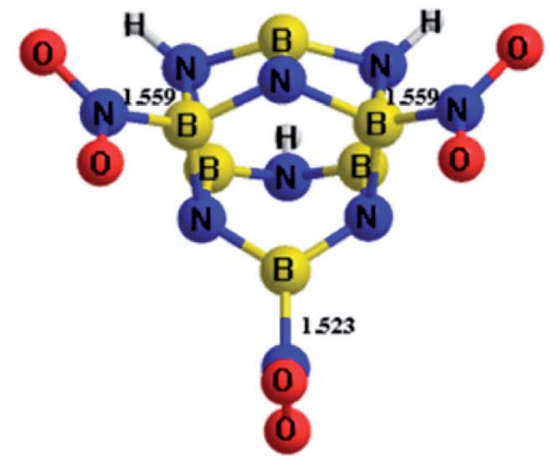

$\mathrm{NO}_{2}-3-1(\mathrm{Cs})$

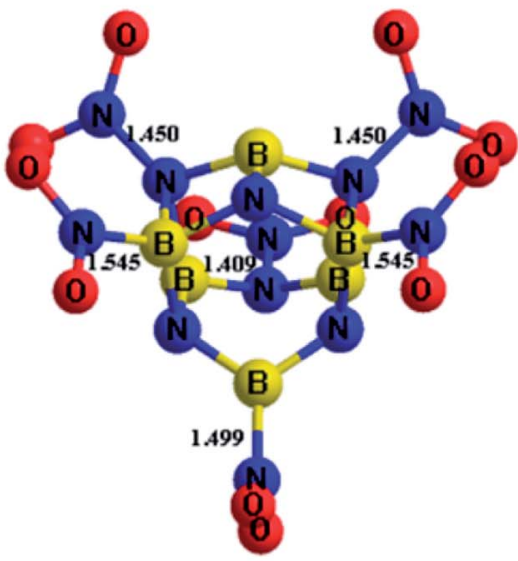

$\mathrm{NO}_{2}-6-1(\mathrm{Cs})$

Fig. 2 Optimized geometries (bond lengths in $\AA$ ) at the M06-2X/6-311++G** level for the $\mathrm{NO}_{2}-n-1(n=1-6)$. Symmetries are labeled in parentheses.

more changes to the skeleton compared with the boron atoms. It should be pointed out that $\mathrm{NO}_{2}-1-3$ has the most skeleton changes among the four isomers, caused by the breaking of the B3-N7 bond. Negative values of $\triangle B D E$ suggest that the bond strengths of all the cage- $\mathrm{NO}_{2}$ bonds are lower than that of the corresponding cage- $\mathrm{H}$ bonds.

To further study the stability of the mononitro-substituted $\mathrm{BN}$-cage isomers, the deformation energies of the $\mathrm{BN}$-cage skeletons $\left(\Delta E_{\text {cage }}^{*}\right)$, the deformation energies of the nitro groups $\left(\Delta E_{\mathrm{NO}_{2}}^{*}\right)$, and the relative $\mathrm{BDE}$ of the cage- $\mathrm{NO}_{2}$ bonds $\left(\Delta \mathrm{BDE}^{*}\right)$ to $\mathrm{NO}_{2}-1-1$ are calculated and the results are shown in Table 2 .

Table 1 The deformation energies of the $\mathrm{BN}$-cage skeleton $\left(\Delta E_{\text {cage }}, \mathrm{kJ} \mathrm{mol}^{-1}\right)$ and the relative $\mathrm{BDE}\left(\Delta \mathrm{BDE}, \mathrm{kJ} \mathrm{mol}^{-1}\right)$ to the designed $\mathrm{BN}$-cage without substitution

\begin{tabular}{llllll}
\hline Compounds & Methods & $\mathrm{NO}_{2}-1-1$ & $\mathrm{NO}_{2}-1-2$ & $\mathrm{NO}_{2}-1-3$ & $\mathrm{NO}_{2}-1-4$ \\
\hline$\Delta E_{\text {cage }}$ & M06-2X & 0.5 & 1.6 & 53.4 & 44.4 \\
& WB97XD & 2.83 & 4.0 & 54.0 & 43.4 \\
$\Delta$ BDE & B3LYP & 3.9 & 1.6 & 55.5 & 30.5 \\
& M06-2X & -24.6 & -55.4 & -212.8 & -226.8 \\
& WB97XD & -39.5 & -62.8 & -226.2 & -241.4 \\
& B3LYP & -37.0 & -61.0 & -225.5 & -228.2
\end{tabular}

As shown in Table 2, comparing with $\mathrm{NO}_{2}-1-1$, the decrease of the $\mathrm{BDE}$ of the $\mathrm{B}-\mathrm{NO}_{2}$ bond in the $\mathrm{NO}_{2}-1-2$ structure leads to an increase of its energy, and the deformation of its skeleton could be ignored due to its small $\Delta E_{\text {cage }}^{*}$ value. For the $\mathrm{N}$ mononitrosubstituted isomers $\mathrm{NO}_{2}-1-3$ and $\mathrm{NO}_{2}-1-4$, the difference of the $\mathrm{B}-\mathrm{NO}_{2}$ and $\mathrm{N}-\mathrm{NO}_{2}$ bond is the primary reason leading to their energy increase. Compared to the global

Table 2 The relative energies $\left(\Delta E, \mathrm{~kJ} \mathrm{~mol}^{-1}\right)$, relative $\mathrm{BDE}$ $\left(\triangle \mathrm{BDE}^{*}, \mathrm{~kJ} \mathrm{~mol}^{-1}\right)$, and the deformation energies of the $\mathrm{BN}$-cage skeletons $\left(\Delta E_{\text {cage }}^{*}, \mathrm{~kJ} \mathrm{~mol}^{-1}\right)$ and nitro groups $\left(\Delta E_{\mathrm{NO}_{2}}^{*}, \mathrm{~kJ} \mathrm{~mol}^{-1}\right)$ among the mononitro-substituted $\mathrm{BN}$-cage compounds

\begin{tabular}{|c|c|c|c|c|c|}
\hline Compounds & Methods & $\mathrm{NO}_{2}-1-1$ & $\mathrm{NO}_{2}-1-2$ & $\mathrm{NO}_{2}-1-3$ & $\mathrm{NO}_{2}-1-4$ \\
\hline \multirow[t]{3}{*}{$\Delta E$} & M06-2X & 0 & 24.6 & 129.7 & 151.3 \\
\hline & $\omega \mathrm{B} 97 \mathrm{XD}$ & 0 & 20.3 & 124.7 & 149.4 \\
\hline & B3LYP & 0 & 17.2 & 126.0 & 152.4 \\
\hline \multirow[t]{3}{*}{$\Delta E_{\text {cage }}^{*}$} & M06-2X & 0 & -0.2 & -26.0 & -18.9 \\
\hline & $\omega \mathrm{B} 97 \mathrm{XD}$ & 0 & -0.2 & -45.7 & -35.8 \\
\hline & B3LYP & 0 & -1.3 & -50.2 & -48.1 \\
\hline \multirow{3}{*}{$\Delta E_{\mathrm{NO}_{2}}^{*}$} & M06-2X & 0 & -4.2 & -4.7 & -6.1 \\
\hline & $\omega \mathrm{B} 97 \mathrm{XD}$ & 0 & -4.3 & -5.2 & -6.5 \\
\hline & B3LYP & 0 & -3.2 & -3.0 & -4.5 \\
\hline \multirow[t]{3}{*}{$\Delta \mathrm{BDE}^{*}$} & M06-2X & 0 & -29.0 & -160.4 & -176.2 \\
\hline & $\omega \mathrm{B} 97 \mathrm{XD}$ & 0 & -24.7 & -175.6 & -191.6 \\
\hline & B3LYP & 0 & -22.9 & -179.3 & -204.9 \\
\hline
\end{tabular}




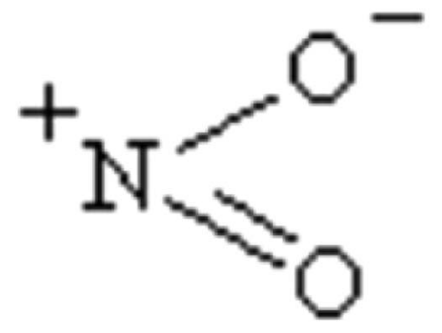

Fig. 3 The valence-bond structures of the nitro group.

minimum of $\mathrm{NO}_{2}-1-1$, the $\mathrm{NO}_{2}$ bonding in the $\mathrm{N}$ atom brings the relative heavy deformation of the $\mathrm{BN}$-cage skeletons, which is another reason for the lower $\mathrm{NO}_{2}-1-3$ and $\mathrm{NO}_{2}-1-4$ structural stability. For the nitro group, the isomers have a small $\Delta E_{\mathrm{NO}_{2}}^{*}$ value and the change of the $\mathrm{NO}_{2}$ could be ignored, as shown in Table 2.

The charge transfer calculated using the NBO analysis is also employed to analyze the stability differences among the different substitution positions. The valence-bond structure of the nitro group, shown in Fig. 3, indicates that the nitro is an electrophilic group, in which the nitrogen atom tends to combine with the boron atom in the cage to provide a stable configuration. Fig. 4 and Table 3 describe the molecular structures, net charge, charge transfer and $\mathrm{BDE}$ of the cage- $\mathrm{NO}_{2}$ bonds for the mononitro or dinitro-substituted cages. As listed in Table 3, the results show that all the nitro groups in the $\mathrm{B}(\mathrm{N})$ mononitro or dinitro-substituted cages are electron accepters, and the charge transfers of the B-mononitro or dinitrosubstituted cage is always larger than those of the $\mathrm{N}$ mononitro or dinitro-substituted cage, suggesting the higher dissociation energies of the $\mathrm{B}-\mathrm{NO}_{2}$ bonds compared with the $\mathrm{N}-$ $\mathrm{NO}_{2}$ bonds.

The above calculations suggest that the B-nitrosubstituted cages have a relatively better stability than the $\mathrm{N}$ nitrosubstituted cages. As such, the $\mathrm{NO}_{2}-1-1, \mathrm{NO}_{2}-2-1$ and $\mathrm{NO}_{2}-3-1$ structures were selected for further study, as discussed in the subsequent sections.

\subsection{Dynamic simulation}

Based on the above calculation results for the stability of these designed BN-cage derivatives, molecular dynamic calculations of the B-substituted $\mathrm{NO}_{2}-n-1(n=1,2,3)$ structures were carried out to exam their dynamic stability. BOMD were employed to perform the molecular dynamic simulation. The static configurations calculated at the M06-2X/6-311++G** level were run as seeds for the BOMD trajectories using the Gaussian-09 program package. Equilibration steps were performed over 1 ps and production runs are $3 \mathrm{ps}$ long with the time step of $1 \mathrm{fs}$.
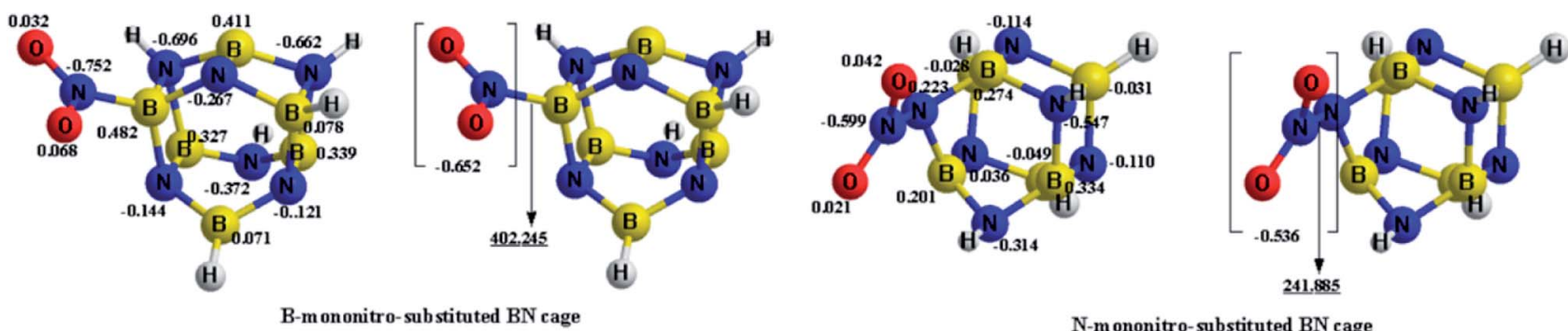

B-mononitro-substituted BN cage
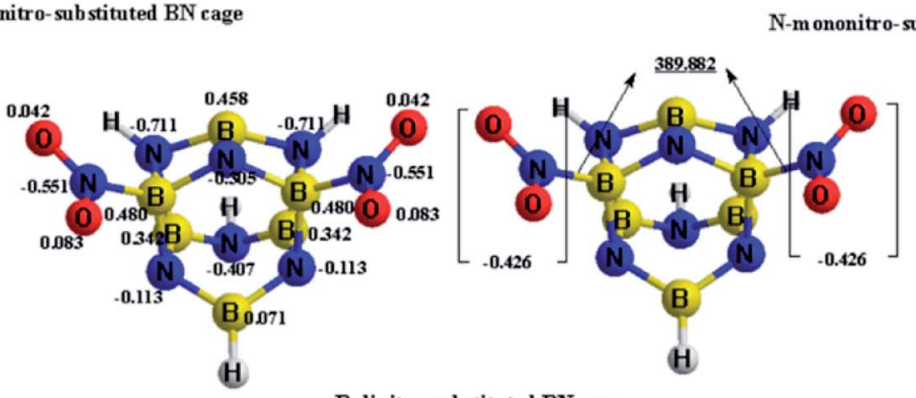

B-dinitro-substituted BN cage
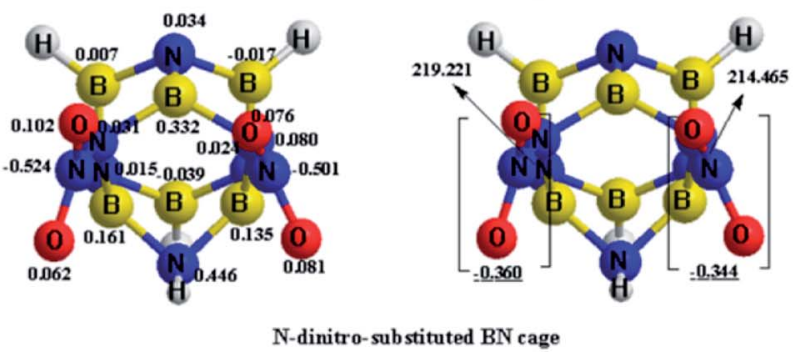

Fig. 4 Optimized geometries, net charge (e), and charge transfer $(e)$ of the $\mathrm{B}(\mathrm{N})$-mononitro(dinitro)-substituted $\mathrm{BN}$-cage compounds at the M06-2X/6-311++G** level. The BDE $\left(\mathrm{KJ} \mathrm{mol}^{-1}\right)$ of the cage- $\mathrm{NO}_{2}$ bonds are underlined. 
Table 3 The net charge $(e)$ on the nitro groups in the $\mathrm{B}(\mathrm{N})$-mononitro(dinitro)-substituted $\mathrm{BN}$-cage compounds at the M06-2X/6$311++G^{* *}, \omega B 97 X D / 6-311++G * *$, and B3LYP/6-311++G** levels

\begin{tabular}{lllll}
\hline & & \multicolumn{4}{l}{ Net charge } \\
\cline { 3 - 5 } Compounds & $\begin{array}{l}\text { Substitution } \\
\text { positions }\end{array}$ & M06-2X & wB97XD & B3LYP \\
\hline B-mononitro-substitution & $\mathrm{B}$ & -0.652 & -0.627 & -0.740 \\
N-mononitro-substitution & $\mathrm{N}$ & -0.536 & -0.497 & -0.504 \\
B-dinitro-substitution & $\mathrm{B}$ & -0.426 & -0.388 & -0.696 \\
& $\mathrm{~B}$ & -0.426 & -0.388 & -0.696 \\
N-dinitro-substitution & $\mathrm{N}$ & -0.360 & -0.322 & -0.349 \\
& $\mathrm{~N}$ & -0.344 & -0.317 & -0.349 \\
\hline
\end{tabular}

The simulation results of the $\mathrm{NO}_{2}-n-1(n=1,2,3)$ structures show that the $\mathrm{NO}_{2}-1-1$ and $\mathrm{NO}_{2}-2-1$ remain stable at $298 \mathrm{~K}$ during the whole simulation, while the nitro groups in $\mathrm{NO}_{2}-3-1$ cannot remain stable at $298 \mathrm{~K}$, as shown in Fig. 5 . As can be seen from Fig. 5, the nitro groups in $\mathrm{NO}_{2}-3-1$ decompose from the cage with the cage- $\mathrm{NO}_{2}$ bond breaking. Oxygen atoms in the nitro groups in the $\mathrm{NO}_{2}-3-1$ bond with the cage directly at $298 \mathrm{~K}$, with $\mathrm{B}-\mathrm{O}$ bond lengths of 1.452 and $1.316 \AA$, while the NO groups decompose from the BN-cage compounds, with the distances between $\mathrm{O}$ and NO groups being $\sim 1.55 \AA$. Moreover, deformation of the cage skeleton occurs with the distance between $\mathrm{B} 5$ and N6 being $2.821 \AA$. Thus, the $\mathrm{NO}_{2}-3-1$ structure cannot remain stable at room temperature. Above all, the $\mathrm{NO}_{2}$ 1-1 and $\mathrm{NO}_{2}-2-1$ structures have exhibited an attractive potential for application in the areas of energetic materials and the details are discussed in the following study on detonation performance.

\subsection{Detonation performance}

In order to quantitatively evaluate the detonation performance of the $\mathrm{NO}_{2}-1-1$ and $\mathrm{NO}_{2}-2-1$ structures, the predicted density $(\rho)$, enthalpy of sublimation $\left(\Delta H_{\text {sub }}^{\circ}\right)$, solid phase enthalpy of

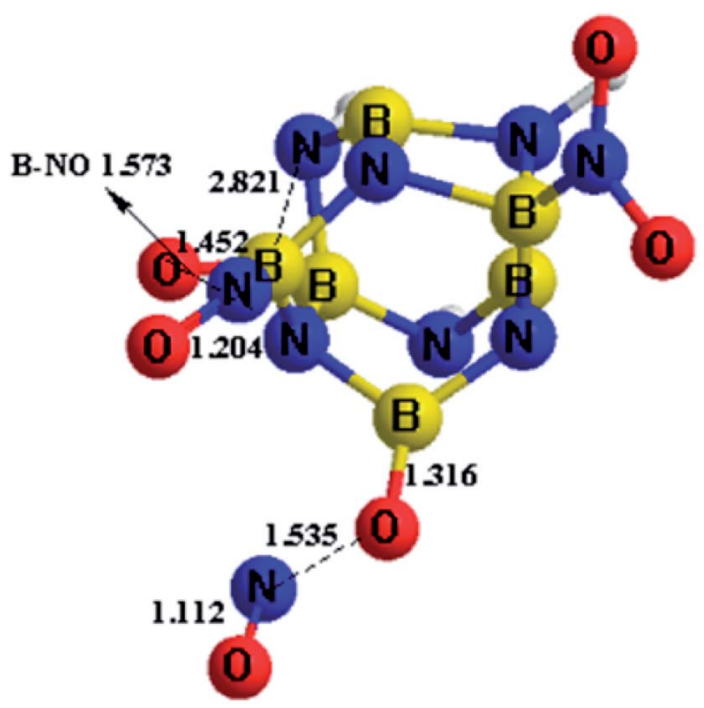

Fig. 5 The dynamic simulation results of $\mathrm{NO}_{2}-3-1$ at $298 \mathrm{~K}$, taken from the simulations performed at the M06-2X/6-311++G** level. formation $\left(\Delta_{\mathrm{f}} H^{\circ}(\mathrm{s})\right)$, oxygen balance and detonation parameters $(Q, D, P)$ were calculated systematically using EXPLO 5 . The results, together with the related information for CL-20, are listed in Table 4 for comparison.

The results in Table 4 show that the $\rho$ of $\mathrm{NO}_{2}-1-1$ and $\mathrm{NO}_{2}-2-1$ are $1.808 \mathrm{~g} \mathrm{~cm}^{-3}\left(1.789 \mathrm{~g} \mathrm{~cm}^{-3}, 1.732 \mathrm{~g} \mathrm{~cm}^{-3}\right)$ and $1.931 \mathrm{~g} \mathrm{~cm}^{-3}$ (1.871 $\mathrm{g} \mathrm{cm}^{-3}, 2.059 \mathrm{~g} \mathrm{~cm}^{-3}$ ) respectively at the M06-2X $(\omega \mathrm{B} 97 \mathrm{XD}, \mathrm{B} 3 \mathrm{LYP}) / 6-311++\mathrm{G}^{* *}$ level. In the meantime, the calculated densities of CL-20 are $1.954 \mathrm{~g} \mathrm{~cm}^{-3}$ at the M06-2X level, $1.907 \mathrm{~g} \mathrm{~cm}^{-3}$ at the $\omega$ B97XD level and $2.022 \mathrm{~g} \mathrm{~cm}^{-3}$ at the B3LYP level, which indicates the relatively high densities of these two newly proposed designed molecules. The $Q$ of $\mathrm{NO}_{2}-2-1$ is $31.25 \%$ (M06-2X), $31.26 \%$ ( $\omega \mathrm{B} 97 \mathrm{XD})$ or $24.79 \%$ (B3LYP) higher than that of CL-20 (6314 $\left.\mathrm{kJ} \mathrm{kg}^{-1}\right)$, with a $D$ of over $6800 \mathrm{~m} \mathrm{~s}^{-1}$. The superior detonation heat of both the $\mathrm{NO}_{2}-1-1$ and $\mathrm{NO}_{2}-2-1$ structures indicate the great potential of these two energetic compounds to be HEDMs.

\subsection{Sensitivity and safety}

To test the sensitivity and safety of the above $\mathrm{NO}_{2}-1-1$ and $\mathrm{NO}_{2}$ 2-1 structures, two methods have been employed in the present work: (1) impact sensitivity; and (2) BDE of the trigger bonds.

3.5.1 Impact sensitivity. The impact sensitivity is a crucial parameter responsible for effectiveness. It reflects whether the explosive is stable enough to be handled or stored under typical conditions. In this paper, the theoretical impact sensitivity of $\mathrm{NO}_{2}-1-1, \mathrm{NO}_{2}-2-1$ and CL-20 were calculated at the M06-2X, $\omega$ B97XD and B3LYP level to compare their safety and practicability (see Table 5). The calculation results show that the $h_{50}$ of the $\mathrm{NO}_{2}-1-1$ and $\mathrm{NO}_{2}-2-1$ structures were $49.498 \mathrm{~cm}(47.745 \mathrm{~cm}$, $50.555 \mathrm{~cm})$ and $34.459 \mathrm{~cm}(34.089 \mathrm{~cm}, 36.115 \mathrm{~cm})$ at the M06-2X ( $\omega$ B97XD, B3LYP)/6-311++G** level, respectively, which are higher than that of CL-20. Such a result illustrates their high value of application.

3.5.2 Bond dissociation energy. The BDE of the trigger bond is often a key factor in investigating the thermal stability and pyrolysis mechanism of energetic compounds. Generally, the smaller the energy needed for breaking a bond, the weaker the bond.

To elucidate the pyrolysis mechanism and thermal stability of the $\mathrm{NO}_{2}-1-1$ and $\mathrm{NO}_{2}-2-1$ structures, the bond dissociation energies of the cage- $\mathrm{NO}_{2}$ bonds in $\mathrm{NO}_{2}-1-1, \mathrm{NO}_{2}-2-1$ and CL-20, as well as the corresponding WBI have been investigated in the present work, as shown in Table 6. Obviously, the BDE of the cage- $\mathrm{NO}_{2}$ bonds in the $\mathrm{NO}_{2}-1-1$ and $\mathrm{NO}_{2}-2-1$ structures are $402.245 \mathrm{~kJ} \mathrm{~mol}^{-1}$ (447.635 $\left.\mathrm{kJ} \mathrm{mol}^{-1}, 393.573 \mathrm{~kJ} \mathrm{~mol}^{-1}\right)$ and $389.882 \mathrm{~kJ} \mathrm{~mol}^{-1}\left(358.869 \mathrm{~kJ} \mathrm{~mol}^{-1}, 381.905 \mathrm{~kJ} \mathrm{~mol}^{-1}\right)$ with WBI of $0.6640(0.6657,0.6852)$ and $0.6716(0.6731,0.6916)$ respectively, at the M06-2X ( $\omega$ B97XD, B3LYP)/6-311++G** level. Thus, the designed $\mathrm{NO}_{2}-1-1$ and $\mathrm{NO}_{2}-2-1$ BN-cage molecules meet the stability requirement suggested previously, that is, a molecule could be considered as a practical energetic material if it has its BDE larger than $84 \mathrm{~kJ} \mathrm{~mol}^{-1}$. Moreover, the BDE of the cage- $\mathrm{NO}_{2}$ bonds in $\mathrm{NO}_{2}-1-1$ and $\mathrm{NO}_{2}-2-1$ are much higher than that of CL20 at the same calculation level, which implies that they have a better stability than CL-20. 
Table 4 Theoretical density $(\rho)$, enthalpy of sublimation $\left(\Delta H_{\text {sub }}^{\circ}\right)$, solid phase enthalpy of formation $\left(\Delta_{f} H^{\circ}(s)\right)$, detonation velocity $(D)$, detonation pressure $(P)$, heat of detonation $(Q)$ and oxygen balance of the $\mathrm{NO}_{2}-1-1$ and $\mathrm{NO}_{2}-2-1$ structures. Experimental parameters of $C L-20$ are labeled in parentheses (the theoretical densities of CL-20 are $1.954 \mathrm{~g} \mathrm{~cm}^{-3}$ at M06-2X, $1.907 \mathrm{~g} \mathrm{~cm}^{-3}$ at $\omega$ B97XD and $2.022 \mathrm{~g} \mathrm{~cm}-3$ at B3LYP)

\begin{tabular}{|c|c|c|c|c|c|c|c|}
\hline \multirow{2}{*}{$\begin{array}{l}\text { compounds } \\
\text { Methods }\end{array}$} & \multicolumn{3}{|l|}{$\mathrm{NO}_{2}-1-1$} & \multicolumn{3}{|l|}{$\mathrm{NO}_{2}-2-1$} & \multirow[b]{2}{*}{ CL-20 } \\
\hline & M06-2X & $\omega \mathrm{B} 97 \mathrm{XD}$ & B3LYP & M06-2X & $\omega \mathrm{B} 97 \mathrm{XD}$ & B3LYP & \\
\hline$\rho\left(\mathrm{g} \mathrm{cm}^{-3}\right)$ & 1.808 & 1.789 & 1.732 & 1.931 & 1.871 & 2.059 & (2.04) \\
\hline$\Delta H_{\mathrm{sub}}^{\circ}\left(\mathrm{kJ} \mathrm{mol}^{-1}\right)$ & 124.900 & 123.909 & 125.908 & 132.842 & 134.435 & 137.619 & - \\
\hline$\Delta_{\mathrm{f}} H^{\circ}(\mathrm{s})\left(\mathrm{kJ} \mathrm{mol}^{-1}\right)$ & -289.545 & -269.297 & -274.313 & -449.511 & -413.859 & -554.623 & - \\
\hline$D\left(\mathrm{~m} \mathrm{~s}^{-1}\right)$ & 6485.349 & 6409.758 & 6132.865 & 7222.655 & 6881.267 & 7019.696 & $(9580)$ \\
\hline$P(\mathrm{GPa})$ & 15.449 & 14.783 & 13.427 & 24.959 & 18.518 & 26.566 & $(43.2)$ \\
\hline$Q\left(\mathrm{~kJ} \mathrm{~kg}^{-1}\right)$ & 8131.956 & 8180.25 & 8115.766 & 8287.309 & 8287.938 & 7879.410 & $(6314)$ \\
\hline Oxygen balance & $-76.011 \%$ & & & $-45.720 \%$ & & & $-10.953 \%$ \\
\hline
\end{tabular}

Table 5 Calculated impact sensitivity $\left(h_{50}\right)$ of the predicted BN-cage compounds and CL-20. Experimental parameters of CL-20 are labeled in parentheses

\begin{tabular}{llrrr}
\hline Compounds & Methods & $\mathrm{NO}_{2}-1-1$ & $\mathrm{NO}_{2}-2-1$ & \multicolumn{1}{c}{ CL-20 } \\
\hline$\sigma_{+}{ }^{2}$ & M06-2X & 292.859 & 417.062 & 231.351 \\
& $\omega$ B97XD & 302.761 & 437.273 & 233.923 \\
$\nu$ & B3LYP & 278.559 & 422.418 & 306.392 \\
& M06-2X & 0.227 & 0.168 & 0.068 \\
& $\omega$ B97XD & 0.220 & 0.167 & 0.065 \\
$h_{50}(\mathrm{~cm})$ & B3LYP & 0.231 & 0.175 & 0.058 \\
& M06-2X & 49.498 & 34.459 & 11.506 \\
& WB97XD & 47.745 & 34.089 & 10.765 \\
& B3LYP & 50.555 & 36.115 & 8.611 \\
& & & &
\end{tabular}

Table 6 Calculated bond dissociation energies (BDE) and Wiberg bond index (WBI) of the trigger bonds (cage- $\mathrm{NO}_{2}$ bonds) in $\mathrm{NO}_{2}-1-1$ and $\mathrm{NO}_{2}-3-1$ at the M06-2X, $\omega$ B97XD and B3LYP level

\begin{tabular}{|c|c|c|c|c|c|c|}
\hline \multirow{2}{*}{$\frac{\text { Compounds }}{\text { Methods }}$} & \multicolumn{3}{|l|}{ WBI } & \multicolumn{3}{|c|}{$\mathrm{BDE}\left(\mathrm{kJ} \mathrm{mol}^{-1}\right)$} \\
\hline & M06-2X & $\omega \mathrm{B} 97 \mathrm{XD}$ & B3LYP & M06-2X & $\omega \mathrm{B} 97 \mathrm{XD}$ & B3LYP \\
\hline $\mathrm{NO}_{2}-1-1$ & 0.6640 & 0.6657 & 0.6852 & 402.245 & 447.635 & 393.573 \\
\hline $\mathrm{NO}_{2}-2-1$ & 0.6716 & 0.6731 & 0.6916 & 389.882 & 358.869 & 381.905 \\
\hline CL-20 & 0.9421 & 0.9460 & 0.9318 & 153.092 & 127.022 & 148.656 \\
\hline
\end{tabular}

\section{Conclusions}

Inspired by the high combustion heat of the boron atom and the large strain energy of the HNIW cage skeleton, we proposed several molecules with a new $\mathrm{BN}$-cage skeleton by replacing $\mathrm{C}$ with $\mathrm{B}$ atoms in this study. A series of energetic molecules $\mathrm{B}_{6}$ $\mathrm{N}_{6} \mathrm{H}_{6-n}\left(\mathrm{NO}_{2}\right)_{n}(n=1-6)$ were subsequently constructed through systematically substituting $\mathrm{NO}_{2}$ groups for the $\mathrm{H}$ atoms of the $\mathrm{BN}$-cage. Then, all the $\mathrm{B}_{6} \mathrm{~N}_{6} \mathrm{H}_{6-n}\left(\mathrm{NO}_{2}\right)_{n}(n=1-6)$ structures were optimized at the M06-2X/6-311++G**, $\omega \mathrm{B} 97 \mathrm{XD} / 6-311++\mathrm{G}^{* *}$ and B3LYP/6-311++G** level of DFT. Analysis of the structural changes caused by substituting the $\mathrm{NO}_{2}$ and the electronic structures including ELF, WBI, charge transfer and BDE reveal the essence of the stability and chemical characteristics of these $\mathrm{B}_{6} \mathrm{~N}_{6} \mathrm{H}_{6-n}\left(\mathrm{NO}_{2}\right)_{n}(n=1-6)$ molecules. The results show that these B-nitro substituted cages have a higher stability than the
N-nitro substituted cages. The corresponding molecular dynamic simulations, which were performed to test the stability of $\mathrm{NO}_{2}-1-1, \mathrm{NO}_{2}-2-1$ and $\mathrm{NO}_{2}-3-1$, indicate that only the $\mathrm{NO}_{2}-1-1$ and $\mathrm{NO}_{2}-2-1$ structures remain stable under ambient conditions. Then, the density, detonation performance and safety of the $\mathrm{NO}_{2}-1-1$ and $\mathrm{NO}_{2}-2-1$ structures were calculated systematically. The results show that the two BN-cage energetic molecules have a much higher detonation heat than traditional energetic materials such as CL-20, due to their high densities and the particular characteristics of the "BN" groups. Calculations also showed much higher $h_{50}$ values of $\mathrm{NO}_{2}-1-1(49.489 \mathrm{~cm}$ at the M06-2X level) and $\mathrm{NO}_{2}-2-1$ (34.459 cm at the M06-2X level) than CL-20 (11.506 $\mathrm{cm}$ at the M06-2X level) in the same level of calculation, as well as the high bond dissociation energies over $84 \mathrm{~kJ} \mathrm{~mol}^{-1}$. Above all, a new type of energetic material based on the BN-cage was put forward and could be a new field of research to find more HEDMs with a superior performance.

\section{Conflicts of interest}

There are no conflicts of interest to declare.

\section{Acknowledgements}

We are indebted to the National Natural Science Foundation of China (21643015 and U1530262). We also acknowledge financial support from the Open Project (LHKF2014-C15) in the Key Laboratory of Theoretical Chemistry of Environment, Ministry of Education.

\section{References}

1 O. S. Bushuyev, P. Brown and A. Maiti, Ionic polymers as a new structural motif for high-energy-density materials, $J$. Am. Chem. Soc., 2012, 134(3), 1422-1425.

2 J. Song, Z. Zhou and X. Dong, Super-high-energy materials based on bis (2, 2-dinitroethyl) nitramine, J. Mater. Chem., 2012, 22(7), 3201-3209.

3 Y. Zhang, D. A. Parrish and J. M. Shreeve, 4-Nitramino-3, 5dinitropyrazole-Based Energetic Salts, Chem.-Eur. J., 2012, 18(3), 987-994. 
4 J. Zhang and J. M. Shreeve, 3, 3'-Dinitroamino-4, 4'azoxyfurazan and its derivatives: an assembly of diverse $\mathrm{N}-\mathrm{O}$ building blocks for high-performance energetic materials, J. Am. Chem. Soc., 2014, 136(11), 4437-4445.

5 D. M. Badgujar, M. B. Talawar and S. N. Asthana, Advances in science and technology of modern energetic materials: an overview, J. Hazard. Mater., 2008, 151(2), 289-305.

6 W. J. Chi and Z. S. Li, Molecular design of prismane-based potential energetic materials with high detonation performance and low impact sensitivity, C. R. Chim., 2015, 18(12), 1270-1276.

7 D. E. Chavez, M. A. Hiskey and R. D. Gilardi, 3, 3'-Azobis (6amino-1, 2, 4, 5-tetrazine): A Novel High-Nitrogen Energetic Material, Angew. Chem., 2000, 112(10), 1861-1863.

8 M. A. Hiskey, N. Goldman and J. R. Stine, High-nitrogen energetic materials derived from azotetrazolate, J. Energ. Mater., 1998, 16(2-3), 119-127.

9 A. Hammerl, T. M. Klapötke and H. Nöth, [N2H5]+ 2 [N4C-N N-CN4] 2-: A New High-Nitrogen High-Energetic Material, Inorg. Chem., 2001, 40(14), 3570-3575.

10 E. G. Gillan, Synthesis of nitrogen-rich carbon nitride networks from an energetic molecular azide precursor, Chem. Mater., 2000, 12(12), 3906-3912.

11 C. Zhang, C. Sun and B. Hu, Synthesis and characterization of the pentazolate anion cyclo-N5 in (N5) 6 (H3O) 3 (NH4) 4Cl, Science, 2017, 355(6323), 374-376.

12 A. T. Nielsen, U.S. Department and Navy, US Pat. Office Application Case No. 70631, 24 June, 1987.

13 K. K. Kuo, G. A. Risha and B. J. Evans, Potential usage of energetic nano-sized powders for combustion and rocket propulsion, MRS Online Proc. Libr., 2003, 800, 3-14.

14 G. Risha, E. Boyer and R. Wehrman. Nano-sized aluminum and boron-based solid fuel characterization in a hybrid rocket engine, 39th AIAA/ASME/SAE/ASEE joint propulsion conference and exhibit, 2003, p. 4593.

15 P. D. McCrary, P. A. Beasley and O. A. Cojocaru, Hypergolic ionic liquids to mill, suspend, and ignite boron nanoparticles, Chem. Commun., 2012, 48(36), 4311-4313.

16 A. MaČeic and J. M. K. Semple, Combustion of boron particles at atmospheric pressure, Combust. Sci. Technol., 1969, 1(3), 181-191.

17 G. Young, K. Sullivan and M. R. Zachariah, Combustion characteristics of boron nanoparticles, Combust. Flame, 2009, 156(2), 322-333.

18 E. C. Koch and T. M. Klapötke, Boron-Based High Explosives, Propellants, Explos., Pyrotech., 2012, 37(3), 335-344.

19 V. I. Pepekin, M. N. Makhov and A. Y. Apin, The reactions of boron in the presence of an explosion, Combust., Explos. Shock Waves, 1972, 8(1), 109-111.

20 L. N. Akimova, A. Y. Apin and L. N. Stesik, Detonation of explosives containing boron and its organic derivatives, Combust., Explos. Shock Waves, 1972, 8(4), 387-390.

$21 \mathrm{~S}$. C. Li and F. A. Williams, Ignition and combustion of boron particles, Int. J. Energ. Mater. Chem. Propul., 1993, 2(1-6), 248-271.

22 J. Frisch, G. W. Trucks, H. B. Schlegel, G. E. Scuseria, M. A. Robb, J. R. Cheeseman, J. A. Montgomery Jr.,
T. Vreven, K. N. Kudin, J. C. Burant, J. M. Millam, S. S. Iyengar, J. Tomasi, V. Barone, B. Mennucci, M. Cossi, G. Scalmani, N. Rega, G. A. Petersson, H. Nakatsuji, M. Hada, M. Ehara, K. Toyota, R. Fukuda, J. Hasegawa, M. Ishida, T. Nakajima, Y. Honda, O. Kitao, H. Nakai, M. Klene, X. Li, J. E. Knox, H. P. Hratchian, J. B. Cross, V. Bakken, C. Adamo, J. Jaramillo, R. Gomperts, R. E. Stratmann, O. Yazyev, A. J. Austin, R. Cammi, C. Pomelli, J. W. Ochterski, P. Y. Ayala, K. Morokuma, G. A. Voth, P. Salvador, J. J. Dannenberg, V. G. Zakrzewski, S. Dapprich, A. D. Daniels, M. C. Strain, O. Farkas, D. K. Malick, A. D. Rabuck, K. Raghavachari, J. B. Foresman, J. V. Ortiz, Q. Cui, A. G. Baboul, S. Clifford, J. Cioslowski, B. B. Stefanov, G. Liu, A. Liashenko, P. Piskorz, I. Komaromi, R. L. Martin, D. J. Fox, T. Keith, M. A. Al-Laham, C. Y. Peng, A. Nanayakkara, M. Challacombe, P. M. W. Gill, B. Johnson, W. Chen, M. W. Wong, C. Gonzalez and J. A. Pople, Gaussian 09, Revision A.02, Gaussian Inc, Wallingford, 2009.

23 W. H. James III, E. G. Buchanan and C. W. Müller, Evolution of amide stacking in larger $\gamma$-peptides: triamide $\mathrm{H}$-bonded cycles, J. Phys. Chem. A, 2011, 115(47), 13783-13798.

24 Y. Zhao and G. T. Donald, Density functionals with broad applicability in chemistry, Acc. Chem. Res., 2009, 41(2), 157-167.

25 J. D. Chai and M. Head-Gordon, Systematic Optimization of Long-range Corrected Hybrid Density Functionals, J. Chem. Phys., 2008, 128, 084106.

26 J. D. Chai and M. Head-Gordon, Long-Range Corrected Hybrid Density Functionals with Damped Atom-Atom Dispersion Corrections, Phys. Chem. Chem. Phys., 2008, 10, 6615-6620.

27 (a) A. D. Becke, Phys. Rev. A, 1988, 38, 3098; (b) J. Becke, Chem. Phys., 1993, 98, 5648.

28 C. Lee, W. Yang and R. G. Parr, Development of the ColleSalvetti correlation-energy formula into a functional of the electron density, Phys. Rev. B: Condens. Matter Mater. Phys., 1988, 37(2), 785.

29 J. Zhang, Q. Zhang and T. T. Vo, Energetic salts with $\pi$ stacking and hydrogen-bonding interactions lead the way to future energetic materials, J. Am. Chem. Soc., 2015, 137(4), 1697-1704.

30 A. G. Roknabadi, M. H. Keshavarz and K. Esmailpour, Structural, thermochemical and detonation performance of derivatives of 1, 2, 4, 5-tetrazine and 1, 4 N-oxide 1, 2, 4, 5tetrazine as new high-performance and nitrogen-rich energetic materials, J. Iran. Chem. Soc., 2017, 14(1), 57-63.

31 J. Yang, X. Gong and G. Wang, Structure, aromaticity, stability, and energetic performance of the analogues and derivatives of s-heptazine, J. Mol. Model., 2014, 20(8), 2379.

32 K. B. Wiberg, Basis set effects on calculated geometries: 6311++ G** vs. aug-cc-pVDZ, J. Comput. Chem., 2004, 25(11), 1342-1346.

33 M. C. Payne, M. P. Teter, D. C. Allan, T. A. Arias and J. D. Joannopoulos, Iterative minimization techniques for $a b$ initio total-energy calculations: molecular dynamics and conjugate gradients, Rev. Mod. Phys., 1992, 64(4), 1045. 
34 M. Suceska, EXPLO5 Program. Version 5.04, Brodarski Institute, Zagreb, Croatia, 2010.

35 P. Politzer and J. S. Murray, Some perspectives on estimating detonation properties of C, H, N, O compounds, Cent. Eur. J. Energ. Mater., 2011, 8(3), 209-220.

36 P. Politzer, J. Martinez, J. S. Murray, M. C. Concha and A. ToroLabbe, An electrostatic interaction correction for improved crystal density prediction, Mol. Phys., 2009, 107(19), 2095-2101.

37 M. Pospíšil, P. Vávra, M. Concha, J. Murray and P. Politzer, A possible crystal volume factor in the impact sensitivities of some energetic compounds, J. Mol. Model., 2010, 16, 895901.

38 E. D. Glendening, J. K. Badenhoop and A. E. Reed, et al., NBO 5.0, Theoretical Chemistry Institute, University of Wisconsin, Madison, WI, 2001, there is no corresponding record for this reference, 2004.

39 A. E. Reed, L. A. Curtiss and F. Weinhold, Intermolecular interactions from a natural bond orbital, donor-acceptor viewpoint, Chem. Rev., 1988, 88(6), 899-926.

40 S. J. Blanksby and G. B. Ellison, Bond dissociation energies of organic molecules, Acc. Chem. Res., 2003, 36(4), 255-263. 